\title{
CHANGES IN PULMONARY PHYSIOLOGY AFTER LUNG VOLUME REDUCTION SURGERY IN A RABBIT MODEL OF EMPHYSEMA
}

Joseph Huh, MD

Matthew Brenner, MD

John C. Chen, MD

Benedict Yoong, BS

Adam Gassel, BS

Fernando Katie, MD

Jeffrey C. Milliken, MD

Robert McKenna, Jr., MD

Richard J. Fischel, MD, PhD

Arthur Gelb, MD

Archie F. Wilson, MD, PhD
Objective: The purpose of this study is to investigate the effects of lung volume reduction surgery on pulmonary compliance, airway flow, and helium lung volumes in an elastase-induced emphysema animal model. Methods: A 15,000-unit bolus of elastase was aerosolized through an endotracheal tube in 14 New Zealand White rabbits to induce emphysema. Stapled lung volume reduction of bilateral upper and middle lobes was performed through a midline sternotomy at 4 weeks after induction of emphysema. Lung functions were measured at baseline before induction of emphysema, preoperatively at 4 weeks, and 1 week postoperatively. Results: Compliance increased after induction of emphysema and decreased in response to lung volume reduction surgery. Functional residual capacity decreased after lung volume reduction surgery in proportion to the amount of excised lung tissue. Expired flows suggested improvement in response to lung volume reduction surgery. Histologic examination confirmed presence of diffuse heterogeneous emphysema in each animal at necropsy. Conclusions: The decreased compliance and increased airway flow after volume reduction surgery in this model parallels findings in human studies and suggests that similar mechanisms of increased elastic recoil and airway support contribute to improvement. (J Thorac Cardiovasc Surg 1998;115:328-35)
$\mathrm{E}_{\mathrm{b}, \mathrm{s}}^{\mathrm{n}}$ mphysema is a chronic lung disease characterized -by progressive destruction of the lung parenchyma leading to changes in pulmonary physiology and mechanics. Lung volume reduction surgery (LVRS) has recently been recognized as a potential palliative treatment approach for emphysema by directly altering some of the adverse pulmonary functional changes. Major underlying abnormalities in emphysematous lungs include hyperinflation and

From the University of California Irvine Medical Center, the Divisions of Cardiothoracic Surgery and Pulmonary Medicine, and Beckman Laser Institute, Irvine, Calif.

Supported by DOE grant DE-FG03-91ER61, ALA grant CI-03017, CTRDRP 6RT0158, and Chapman Medical Center Research Grant.

Read at the Seventy-seventh Annual Meeting of The American Association for Thoracic Surgery, Washington, D.C., May 4-7, 1997.

Received for publication May 7, 1997; revisions requested August 18, 1997; revisions received Sept. 24, 1997; accepted for publication Oct. 7, 1997.

Address for reprints: Matthew Brenner, MD, Pulmonary and Critical Care Medicine Division, University of California Irvine Medical Center, 101 The City Dr., Orange, CA 928683298.

Copyright (C) 1998 by Mosby, Inc.

$0022-5223 / 98 \$ 5.00+0 \quad \mathbf{1 2 / 6 / 8 6 7 2 0}$ airway obstruction. However, the mechanism by which LVRS affects pulmonary physiology and mechanics remains an area of intense investigation.

Previous experience in surgical lung volume reduction has been limited primarily to bullous disease. ${ }^{1}$ The removal of functioning and partially functioning lung parenchymal tissue in heterogeneous emphysema was briefly investigated in the 1950 s and has recently been the subject of renewed interest. $^{2}$ The recent clinical and laboratory animal data in LVRS suggest that a reduction of the lung volume within the thorax results in changes in the mechanics of breathing. ${ }^{3-5}$

We studied the effects of LVRS on pulmonary physiology using an elastase-induced model of purely obstructive emphysema in New Zealand White rabbits. Clinically, bilateral LVRS operations have been shown to provide greater acute lung volume reduction effects than unilateral procedures. ${ }^{6,7}$ Stapled volume reduction has been shown to provide greater improvement in lung function, fewer postoperative complications, and less supplemental oxygen need compared with laser-assisted procedures. $^{8}$ Therefore we investigated bilateral stapled LVRS techniques in our model using a median sternotomy approach. We examined the effects of 
LVRS on lung volumes, compliance, and airflow to determine mechanisms of response and the effects of the amount of tissue removed on lung function.

\section{Methods}

This protocol was approved by the Institutional Animal Care and Use Committee at the University of California, Irvine. All rabbits were cared for in accordance with the National Institutes of Health Guide for the Care and Use of Laboratory Animals.

Animal preparation. Male New Zealand White rabbits (3.0 to $4.5 \mathrm{~kg}$ ) were used for these studies. Rabbits were anesthetized with a 2:1 mixture of ketamine $\mathrm{HCl}(100$ $\mathrm{mg} / \mathrm{ml})$ and xylazine $(20 \mathrm{mg} / \mathrm{ml})$ at a dose of $0.75 \mathrm{ml} / \mathrm{kg}$ intramuscularly. Rabbits were intubated with a $3 \mathrm{~mm}$ endotracheal tube and mechanically ventilated (Harvard Apparatus Dual Phase Control Respiratory Pump Canine, Harvard Apparatus Co., South Natick, Mass.) with a tidal volume of $50 \mathrm{ml}$ and frequency of 3040 breaths $/ \mathrm{min}$. A 20 -gauge intravenous catheter was placed in a marginal ear vein for intravenous access. Anesthesia was maintained with $0.3 \mathrm{ml}$ of $1: 1$ mixture of ketamine $(100 \mathrm{mg} / \mathrm{ml})$ and xylazine $(20 \mathrm{mg} / \mathrm{ml})$ given as an intravenous bolus as needed to maintain apnea throughout all procedures.

Induction of emphysema. Emphysema was induced in anesthetized rabbits by aerosolizing 15,000 units $(7.89 \mathrm{ml})$ of porcine elastase (Product E1250, Sigma Chemical Company, St. Louis, Mo.) through the endotracheal tube over approximately 1 hour. The animals were placed in a prone position during aerosolization of elastase to distribute the elastase relatively equally to the left and right lungs. The nebulizer (Respirgard, Marquest Medical Products, Inc., Englewood, Colo.) was placed in the inspiratory arm of the ventilator circuit. The oxygen flow through the nebulizer was adjusted to maintain the peak airway pressure at $20 \mathrm{~cm} \mathrm{H}_{2} \mathrm{O}$, monitored by a pressure gauge placed at the side port of the endotracheal tube.

Pulmonary function testing. Lung function measurements were obtained at baseline before induction of emphysema, immediately preoperatively at 4 weeks after induction of emphysema, and 1 week after the operation. Static lung compliance, expiratory air flows, and gas dilution lung volumes were measured at each time interval.

Static lung compliance measurement. Static lung compliance pressures were measured at inflation volumes of $60,50,40,30$, and $20 \mathrm{cc}$ inflation above forced residual capacity (FRC). The anesthetized rabbits were taken off the ventilator and placed in the left decubitus position. A $60 \mathrm{cc}$ syringe was attached to the end of the endotracheal tubes, and the lungs were inflated to $60 \mathrm{cc}$ volume above FRC three times to standardize preinflation volumes. The lungs were allowed to passively deflate.

The appropriate volumes were then injected, the syringe was held in place for 5 seconds, static airway pressures were measured, and the syringes were released. The airway pressures were measured by a water manometer (10AA25, Meriam Instruments, Cleveland, Ohio) placed at the endotracheal side port. The rabbits were returned to mechanical ventilation after the measurements.
Dynamic expiratory flow measurement. The anesthetized rabbits were placed into a sealed acrylic plastic box for measurement of forced expiratory flows. The endotracheal tube was connected to an external port through which the rabbits were ventilated while in the box. A pneumotach and flow transducer (MP45-14, Validyne Engineering Corp., Northridge, Calif.) was connected to the external port for air flow measurements. The box was pressurized and maintained at $20 \mathrm{~cm}$ of $\mathrm{H}_{2} \mathrm{O}$ pressure to simulate a forced expiratory maneuver by the rabbits. Volumes of $60 \mathrm{cc}$ greater than FRC were injected in the airway through the pneumotach with a syringe. The syringe was disconnected from the pneumotach, and the rabbit was allowed to exhale the $60 \mathrm{cc}$ through the pneumotach. This expiratory maneuver was repeated four times and averaged for each rabbit.

The expiratory reserve volume (ERV) was determined by connecting a calibrated tube submerged in water to the acrylic plastic box port with the acrylic plastic box at atmospheric pressure. The box was then pressurized to 20 $\mathrm{cm} \mathrm{H}_{2} \mathrm{O}$ causing the rabbit to expire the ERV into the calibrated tube. The displacement of the water in the calibrated tube was measured as the ERV.

To verify that maximal flows were achieved at $20 \mathrm{~cm}$ $\mathrm{H}_{2} \mathrm{O}$, the forced expiratory maneuver was repeated at a higher pressure of $25 \mathrm{~cm} \mathrm{H}_{2} \mathrm{O}$ to demonstrate approximate equivalence of maximal flows.

An analog-to-digital converter (Keithley System 570, Cleveland, Ohio) sampling at $60 \mathrm{~Hz}$ was used to digitize the pressure transducer data, which was then stored on an IBM personal computer (IBM Corp., Armonk, N.Y.). Flow was converted to volume by integration over time. Forced expiratory flows at 40 and $20 \mathrm{cc}$ inflation are calculated from the digital data.

Gas dilution lung volumes. The inhalation gases consisted of $9.30 \%$ helium, $60.50 \%$ oxygen, $29.05 \%$ nitrogen, $0.87 \%$ acetylene, and $0.28 \% \mathrm{C}^{18} \mathrm{O}$ (Liquid Carbonic Corp., Los Angeles, Calif.). All gas concentrations were measured by mass spectrometer (MGA 1100, PerkinsElmer Corp., Pomona, Calif.). The data were converted to digital information by an analog-to-digital converter (Keithley System 570, Cleveland, Ohio) sampling at $20 \mathrm{~Hz}$ and stored on an IBM personal computer.

The anesthetized rabbits were taken off the ventilator and placed in the left decubitus position. The sampling tube of the mass spectrometer was connected to the side port of the endotracheal tube through which the inspired and expired gas concentrations were continuously measured. A syringe was filled to $60 \mathrm{cc}$ with inhalation gasses and connected to the endotracheal tube. A multibreath helium dilution maneuver was performed by manually pumping the syringe for 10 breaths with a tidal volume of $60 \mathrm{cc}$ over 6 to 10 seconds total time. The initial and final helium concentrations were used to calculate the multibreath helium dilution FRC. Two measurements of FRC were obtained at each trial and averaged. The rabbits were returned to mechanical ventilation after each procedure.

LVRS. LVRS was performed 4 weeks after elastase induction of emphysema. The anesthetized and intubated rabbits were shaved and placed in a supine position. Hypothermia was prevented with a surgical warming pad, and lactated Ringer's solution was infused through an 
Table I. Changes in pulmonary physiology

\begin{tabular}{|c|c|c|c|c|c|}
\hline & \multirow[b]{2}{*}{ Baseline } & \multirow[b]{2}{*}{ Preoperative } & \multirow[b]{2}{*}{ Postoperative } & \multicolumn{2}{|c|}{$p$ Values* } \\
\hline & & & & $\begin{array}{c}\text { Baseline, } \\
\text { preoperative }\end{array}$ & $\begin{array}{l}\text { Preoperative, } \\
\text { postoperative }\end{array}$ \\
\hline FRC (cc) & 32.32 & 37.07 & 32.37 & 0.003 & 0.007 \\
\hline $\mathrm{RV}(\mathrm{cc})$ & 21.96 & 25.00 & 21.33 & 0.03 & 0.02 \\
\hline FEF $33 \%(\mathrm{cc} / \mathrm{sec})$ & 221.83 & 184.37 & 197.89 & 0.03 & NS \\
\hline FEF $66 \%(\mathrm{cc} / \mathrm{sec})$ & 182.04 & 159.13 & 172.96 & NS & NS \\
\hline $\mathrm{Gaw}^{*}\left(\mathrm{cc} / \mathrm{sec} / \mathrm{cm} \mathrm{H}_{2} \mathrm{O}\right)$ & 11.86 & 7.46 & 9.88 & NS & NS \\
\hline $\mathrm{SGaw}^{*}\left(1 / \mathrm{sec} / \mathrm{cm} \mathrm{H}_{2} \mathrm{O}\right)$ & 0.38 & 0.21 & 0.31 & NS & NS \\
\hline $\mathrm{P}_{\max } \dagger\left(\mathrm{cm} \mathrm{H} \mathrm{H}_{2} \mathrm{O}\right)$ & 18.86 & 16.71 & 21.07 & 0.0003 & 0.0001 \\
\hline
\end{tabular}

NS, No significance.

* Statistical tests by paired $t$ test with significance at $p<0.5$.

$\dagger$ Gaw and SGaw are average of individual Gaw and SGaw of each rabbit.

$\ddagger \mathrm{P}_{\text {max }}$ is airway pressure at maximal lung inflation.

intravenous catheter in a marginal ear vein at 5 to $15 \mathrm{cc} / \mathrm{hr}$. The rabbits were mechanically ventilated. Oxygen saturation (Ohmeda Biox 3700 pulse oximeter, BOC Health Care, Ohmeda, Liberty Corner, N.J.), tidal carbon dioxide (Ohmeda $5200 \mathrm{CO}_{2}$ monitor, BOC Health Care), and electrocardiogram (Hewlett-Packard 78353B continuous EKG monitor, BioMedical Services, Hewlett-Packard Co., Palo Alto, Calif.) were monitored continuously.

The chest was prepared with povidone-iodine (Betadine) and draped with a sterile drape. The thorax was entered through a median sternotomy. Bilateral upper and middle lobes were excised using a linear thoracoscopic stapler (Endopath ELC, Ethicon Endo-Surgery, Inc., Cincinnati, Ohio) with $3.5 \mathrm{~mm}$ staples. Target quantity of lung tissue removed was 2 to $6 \mathrm{gm}$. Hemostasis was obtained and a $12 \mathrm{~F}$ neonatal chest tube was placed under direct visualization into each pleural space. The two chest tubes were connected to $10 \mathrm{~cm} \mathrm{H}_{2} \mathrm{O}$ suction. The sternum was closed with $0-0$ silk and the chest wound was closed in layers with absorbable monofilament sutures.

The rabbits were awakened from anesthesia and extubated. Usually a small air leak was present in the chest tubes, but all leaks sealed spontaneously within 1 hour. All chest tubes were removed within 1 hour.

Histologic preparation. The animals were killed at 1 week after LVRS. The lungs were removed en bloc and inflated with formalin ( $20 \mathrm{~cm} \mathrm{H}_{2} \mathrm{O}$ pressure) for histologic preparation. The lung sections were prepared at 0.2 to 0.4 $\mathrm{cm}$ thickness and embedded in paraffin. Slides were stained with hematoxylin-eosin and studied by light microscopy.

Statistical analysis. All compliance data, helium volume data, flow data, and histologic grading for each rabbit were tabulated corresponding to baseline, preoperative, and postoperative measurements. Comparisons of baseline to preoperative values and preoperative to postoperative values were made using paired Student's $t$ test. The flow data at $20 \mathrm{~cm} \mathrm{H}_{2} \mathrm{O}$ pressures were compared with flows at $25 \mathrm{~cm} \mathrm{H}_{2} \mathrm{O}$ pressure using paired Student's $t$ test. Correlation analysis was performed using the Pearson correlation coefficient.

\section{Results}

All rabbits that were successfully induced with emphysema survived the LVRS. Mortality from the elastase induction of emphysema was approximately 10\%. Resected lung quantities averaged 3.37 gm, with range of 1.8 to $5.8 \mathrm{gm}$.

Lung volumes. The waveforms of the helium multibreath maneuver show a relatively steady plateau at the final concentration, which suggests that effective mixing of the alveolar volume occurred (Fig. 1). The multibreath helium dilution lung volumes showed significantly increased FRC after induction of emphysema. This volume decreased in response to LVRS (Table I). The decrease in lung volume correlated with the quantity of excised lung tissue (Fig. 2, Pearson correlation, $r=0.54, p=$ 0.047). Residual volumes were calculated by subtracting the measured ERV expired at $20 \mathrm{~cm} \mathrm{H}_{2} \mathrm{O}$ pressure in the pressure box from the measured FRC for each rabbit. The residual volumes showed a similar significant trend after induction of emphysema and LVRS (Table I).

Compliance. The pressures measured from 60 , $50,40,30$, and $20 \mathrm{cc}$ greater than FRC were adjusted for the measured FRC and averaged to assess lung compliance. The pressures at a given volume decreased with the induction of emphysema and increased after surgical volume reduction (Fig. 3). The difference in the pressures between each of the three curves was significant (paired $t$ test, $p<0.05$ ). The change in compliance as measured by percent change static airway pressures at maximal inflation correlated with increasing quantity of excised lung (Fig. 4, Pearson correlation, $r=0.74, p=0.0024$ ). 


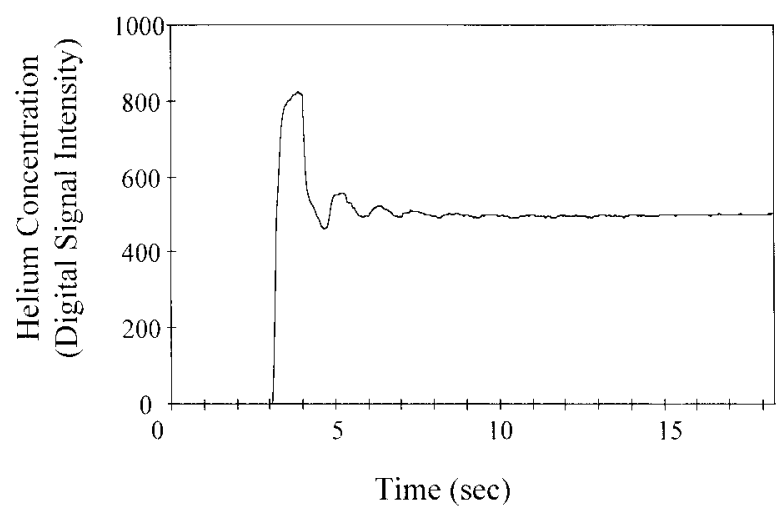

Fig. 1. Multibreath gas dilution lung volume measurement. Figure shows continuous helium gas concentration measured as digital signal intensity from a mass spectrometer. Helium concentration reaches a stable final concentration within four to five breaths, with no delayed mixing. $F R C$, Forced residual capacity; LVRS, lung volume reduction surgery.

Expiratory flows. Forced expiratory air flows were assessed at $33 \%\left(\mathrm{FEF}_{33}\right)$ and $66 \%\left(\mathrm{FEF}_{66}\right)$ of expired volume with $20 \mathrm{~cm} \mathrm{H}_{2} \mathrm{O}$ body box pressure. $\mathrm{FEF}_{33}$ showed significant decrease in expiratory flows with the induction of emphysema. The expiratory flows increased after LVRS, although this did not reach statistical significance (Table I).

Forced expiratory flow measurements were repeated at $25 \mathrm{~cm} \mathrm{H}_{2} \mathrm{O}$ driving pressure to assess whether, indeed, maximal flows were obtained at 20 $\mathrm{cm} \mathrm{H}_{2} \mathrm{O}$ pressure. The flows at 20 and $25 \mathrm{~cm} \mathrm{H}_{2} \mathrm{O}$ pressure showed a correlation coefficient of 0.9 . The mean difference between each measurement was $3 \%$ with no statistical difference.

Maximal flow-volume relationship. Airway flows at $33 \%$ and $66 \%$ of expiration were plotted against the lung volumes at $33 \%$ and $66 \%$ of expiration to construct the maximal flow-volume relationship (Fig. 5). Airway conductances were calculated (Table I) ${ }^{9}$

Histology. Histologic examination confirmed presence of severe diffuse emphysema in each animal at necropsy (Fig. 6). Each rabbit lung was sectioned into upper, middle, and lower lung fields. The histologic appearance was graded according to the number of alveolar walls counted from an end terminal bronchiole toward the lung periphery. The number of walls in a millimeter was noted. The rabbits induced with emphysema showed an average of 7.88 walls $/ \mathrm{mm}(n=14)$. By contrast, normal rabbits not induced with emphysema showed 14.85

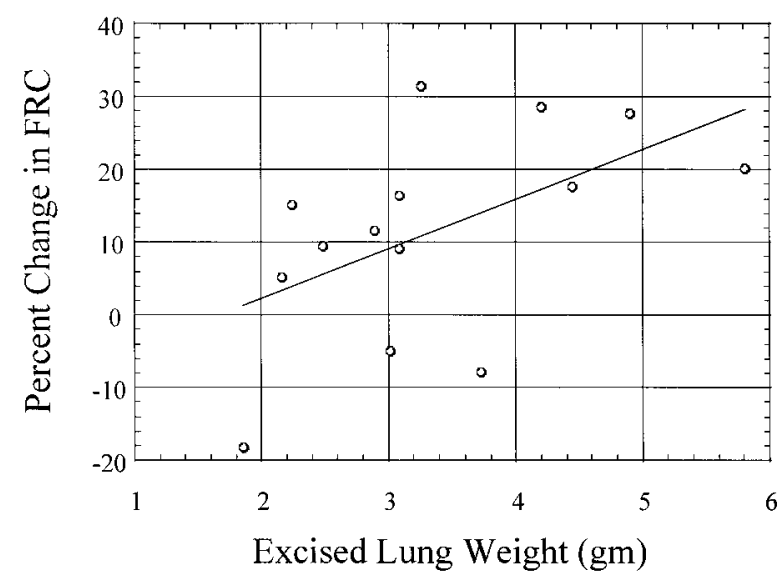

Fig. 2. Change in lung volume. Graph shows effect of increasing lung mass excision on percent change in forced residual capacity $(F R C)$ from preoperative to postoperative measurement $(r=0.54, p=0.047)$. LVRS, Lung volume reduction surgery.

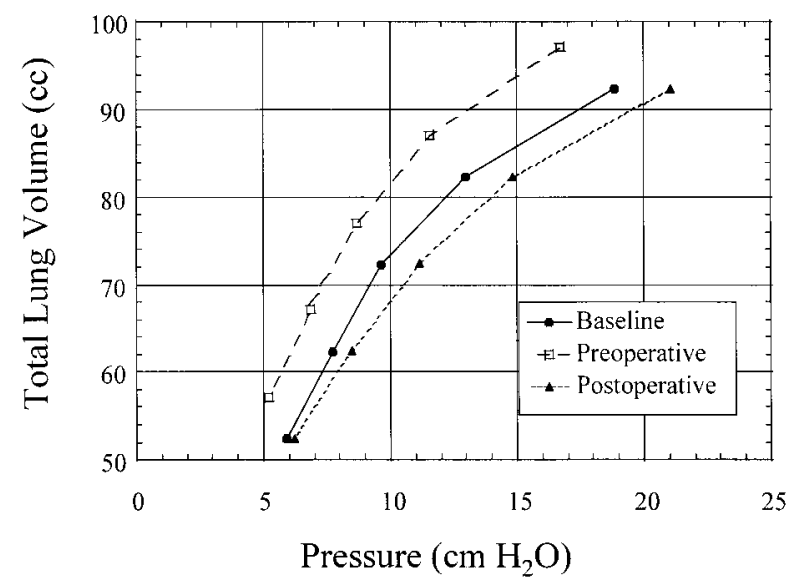

Fig. 3. Static compliance. Graphs shows lung compliance at baseline before induction of emphysema, preoperatively (4 weeks after induction of emphysema), and postoperatively (1 week after surgery).

walls $/ \mathrm{mm}(n=3)$. The difference was statistically significant at $p=0.001$ (Student's $t$ test).

\section{Discussion}

This rabbit model illustrates key pulmonary physiologic changes that take place in response to induction of emphysema and operative volume reduction. Elastase induction of emphysema results in increased lung volume with corresponding increased compliance and decreased airflows analogous to changes seen in patients with emphysema. The data 


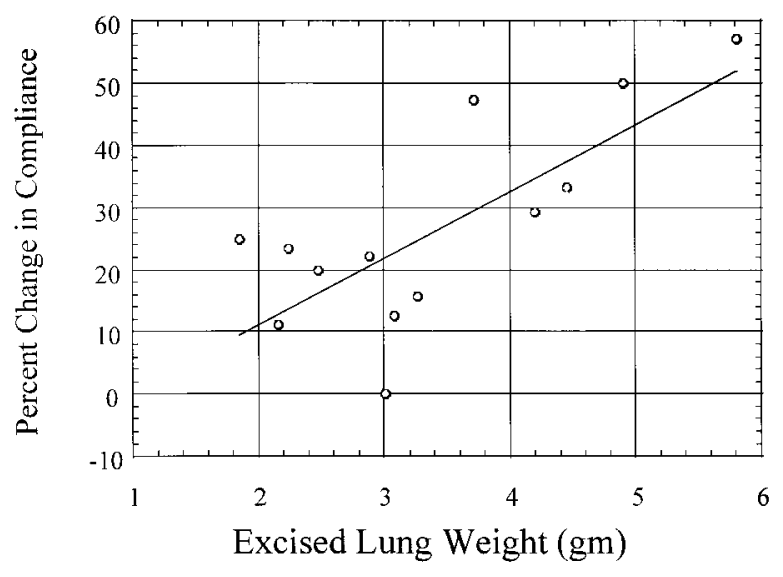

Fig. 4. Change in compliance. Graph shows effect of increasing lung mass excision on percent change in maximal airway pressure at $60 \mathrm{cc}$ inflation from preoperative to postoperative measurement $(r=0.74, p=0.0024)$. LVRS, Lung volume reduction surgery.

also show partial reversal of these changes with LVRS.

As seen in clinical studies with emphysematous patients, a significant increase in elastic recoil occurs after LVRS demonstrated by the lung compliance curves in this model (Fig. 3). Rabbit lungs have greater recoil at any given volume after LVRS. Furthermore, the change in compliance shows a direct correlation with the amount of excised lung. As the quantity of excised lung increased, a greater change was observed in airway pressures (Fig. 4), without evident maximal resection quantity up to 5 gm in this study. This suggests that larger tissue resection may provide improved results in compliance, unless other physiologic variables limit lung resection to a lower, optimal quantity.

Measurement of expiratory flow shows a trend toward increases in mean flows after LVRS, although the improvements were variable and did not reach statistical significance. Recoil-adjusted flows improved similarly and suggest improvement in airway conductance beyond the improved compliance and recoil. Mean calculated airway conductance (Gaw) did suggest improvements in airway conductance (Table I).

Measured volumes, FRC, and residual volume, both significantly increased in response to induction of emphysema and decreased after LVRS. The ability to affect lung volume by excising lung mass is fundamental in LVRS. Data in this animal model

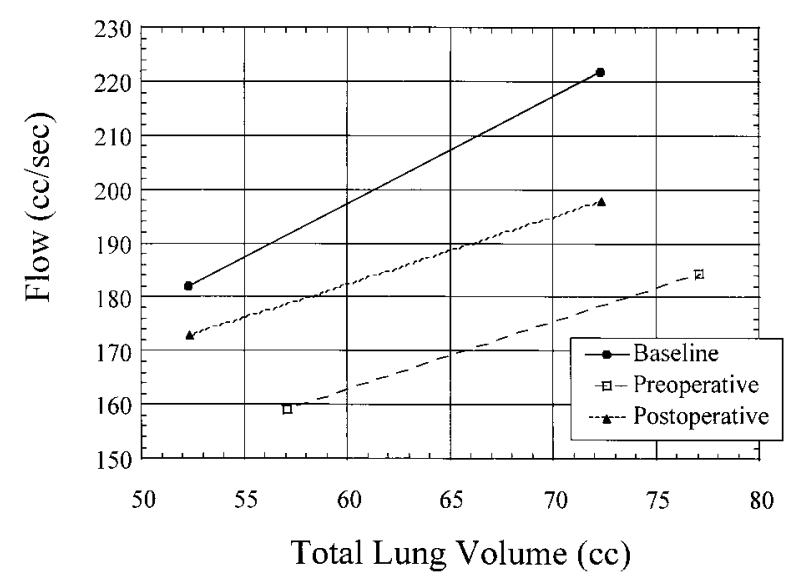

Fig. 5. Flow-volume relationship. Graph shows dynamic flow-volume relationship at $33 \%$ and $66 \%$ of exhaled volume at baseline, preoperatively, and postoperatively.

show a positive correlation between quantity of excised lung mass and the magnitude of change in FRC (Fig. 2).

Pulmonary function testing in this animal model was performed through an endotracheal tube with the animals under general anesthesia. Maximal inspiration was simulated by the $60 \mathrm{cc}$ insufflation through the endotracheal tube. Forced expiration was simulated by the $20 \mathrm{~cm}$ driving pressure generated in the pressurized body box. Attainment of maximal flows at $20 \mathrm{~cm} \mathrm{H}_{2} \mathrm{O}$ pressure was important in the flow-pressure analysis. To determine whether maximal flows were obtained, all expiratory flow measurements were repeated at $25 \mathrm{~cm} \mathrm{H}_{2} \mathrm{O}$ pressure. Our data confirm that no increase occurred in flows at the higher driving pressure, and, in fact, flows were close to maximal at $20 \mathrm{~cm} \mathrm{H}_{2} \mathrm{O}$ driving pressure.

Although the $3 \mathrm{~mm}$ pediatric endotracheal tube provided some resistance, this was not the ratelimiting point of the expiration airway. Previous work with 2.5 and $3.5 \mathrm{~mm}$ pediatric endotracheal tubes revealed that at 20 and $25 \mathrm{~cm} \mathrm{H}_{2} \mathrm{O}$ pressure gradient, a proportionate increase occurred in flows through the endotracheal tubes. ${ }^{10}$

The lateral decubitus position was chosen for the static and flow measurements predominantly for logistical reasons, particularly for ensuring that the endotracheal tube is not bent or kinked. It is possible that changes in position during measurements could affect the compliance and flow measurements; however, all measurements in 

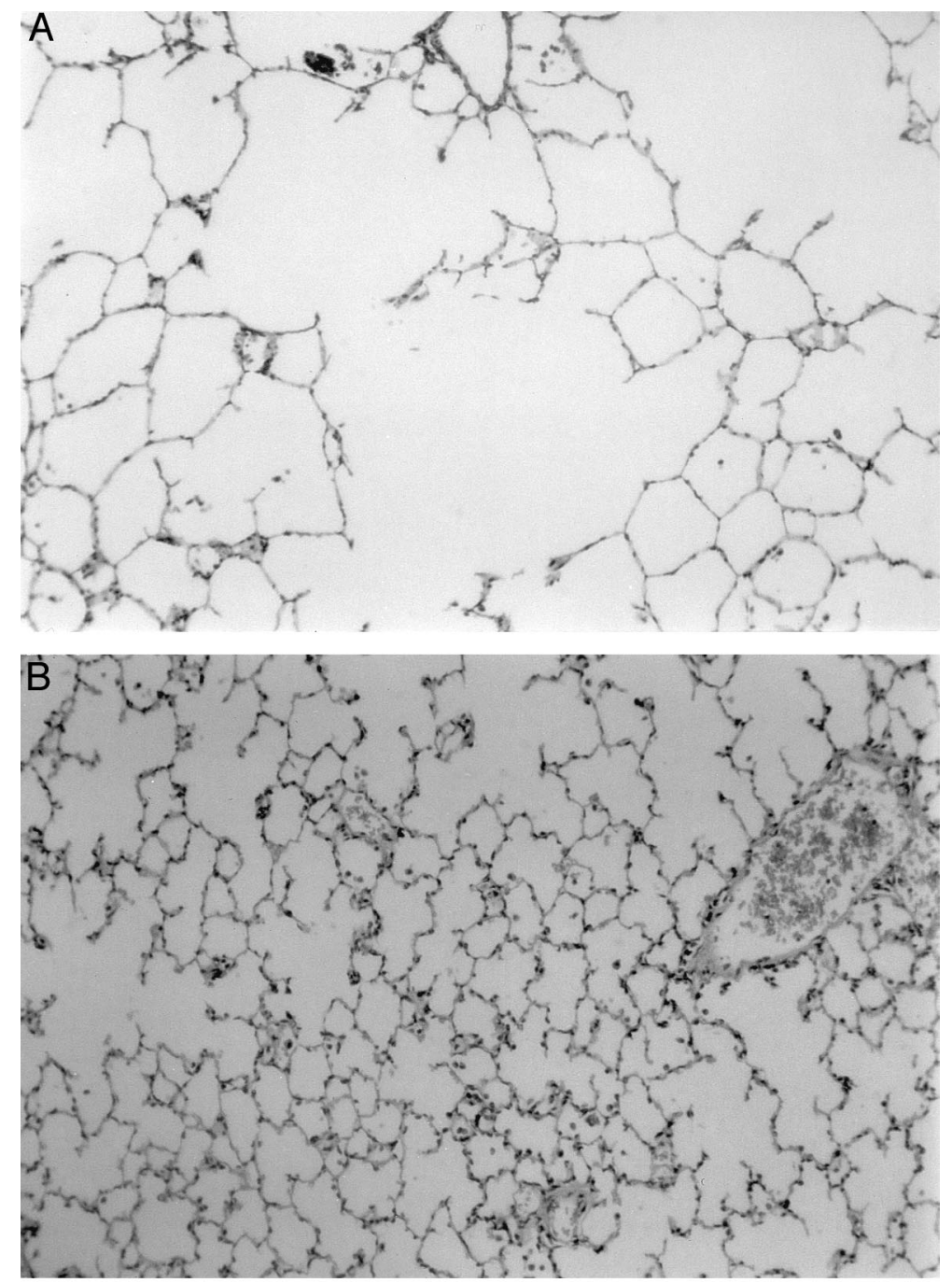

Fig. 6. A, Histologic findings in elastase-induced emphysema. Effect of 15,000 units of aerosolized elastase. Hematoxylin-eosin stain at $10 \times$ magnification. B, Histologic findings of normal rabbit lung. Hematoxylin-eosin stain at $10 \times$ magnification.

these experiments were consistently conducted in the lateral position.

We report static airway pressures here because the rabbit chest wall is very compliant. Our previous experience with esophageal balloon pressures in the rabbit model revealed pressures of approximately -1 $\mathrm{cm} \mathrm{H}_{2} \mathrm{O}$ pressure at $\mathrm{FRC}$ and $+3 \mathrm{~cm} \mathrm{H}_{2} \mathrm{O}$ pressure at total lung capacity. Thus esophageal pressures were essentially stable within the insufflation volumes, and the chest wall had little or no influence on measured static airway pressures. Because the difference between the lung elastic recoil measurement and static airway compliance is the component of chest wall contribution, static airway compliance is a reasonable estimation of static lung elastic recoil in the rabbit under the conditions used in these studies.

Multibreath helium dilution lung volume measurements were performed to assess changes in lung volume. In obstructive lung disease in human beings, the gas dilution method tends to underestimate lung volumes compared with body plethysmography lung volumes because of trapped air that fails to communicate with the inspired and expired samples. ${ }^{11,12}$ In this rabbit model the waveforms of the helium multibreath maneuver suggest that complete 
mixing of the alveolar volume effectively occurred (Fig. 1). This may be attributed to the rapid breathing accomplished by the pumping syringe maneuver, as well as the relatively small volumes of the rabbit lungs and the normally rapid emptying of the rabbit airways.

The degree of emphysema produced in these animals is mild to moderate. If a more severe degree of emphysema could be induced, a greater slope of helium dilution curves might be expected. Future studies will be required to determine whether the degree of air trapping and heterogeneity of emphysema will predict response to LVRS.

We chose to preferentially resect the upper lobes and middle lobes to parallel most clinical operations performed on patients. The resections were not directed specifically at areas of emphysema. Emphysema in these animals tended to be centrilobular and relatively diffuse. We observed the rabbits 1 week before they were killed. The rabbits had recovered almost fully by 1 week. The sternotomy incisions and the lung staple lines were well healed histologically with no significant postoperative inflammation.

One hypothesis of physiologic improvement after LVRS proposed in human beings is that nonfunctioning, nonventilating lung tissue is removed, allowing the surrounding "compressed normal" tissue to expand. ${ }^{13}$ However, in the rabbit model used in the current studies, the excised parenchymal tissue included both partially functioning and normally functioning respiratory units. These data and others ${ }^{2}$ suggest that improvements in compliance and elastic recoil after LVRS may occur after removal of low ventilation/perfusion units, or even units with similar function to the remaining lung, and may not be limited to removal of nonfunctioning pulmonary units.

This rabbit emphysema LVRS model shows significant increase in lung recoil and is consistent with an increase in airway support after volume reduction. These findings parallel human data and may indicate that similar mechanisms contribute to improvement after clinical volume reduction. Furthermore, this model shows that changes in both lung volumes and lung recoil have a positive correlation with the mass of excised lung. This finding suggests that lung volumes and recoil may not be variables that define the optimal quantity of lung excision. Further work is necessary to identify the physiologic factors that will be limiting in LVRS.

\section{REFERENCES}

1. Connolly JE, Wilson A. The current status of surgery for bullous emphysema. J Thorac Cardiovasc Surg 1989;97:35161.

2. Brantigan O, Mueller E, Kress MB. A surgical approach to pulmonary emphysema. Am Rev Respir Dis 1959;80:194-202.

3. Sciurba FC, Rogers RM, Keenan RJ, Slivka WA, Gorcsan J, Ferson PF, et al. Improvement in pulmonary function and elastic recoil after lung-reduction surgery for diffuse emphysema. N Engl J Med 1996;334:1095-9.

4. Brenner M, Yoong B, Budd M, Katie F, Wake T, Mukai D, et al. The effect of lung volume reduction surgery on static compliance and maximal flows in a rabbit model of emphysema. Chest 1996;110(4 Suppl):1775.

5. O'Donnell DE, Webb KA, Bertley JC, Chau LKL, Conlan AA. Mechanisms of relief of exertional breathlessness following unilateral bullectomy and lung volume reduction surgery in emphysema. Chest 1996;110:18-27.

6. Cooper JD, Trulock EP, Triantafillou AN, Patterson GA, Pohl MS, Deloney PA, et al. Bilateral pneumectomy (volume reduction) for chronic obstructive pulmonary disease. J Thorac Cardiovasc Surg 1995;109:106-16.

7. McKenna RJ, Brenner M, Fischel RJ, Gelb AF. Should lung volume reduction for emphysema be unilateral or bilateral? J Thorac Cardiovasc Surg 1996;112:1331-9.

8. McKenna RJ, Brenner M, Gelb AF, Mullin M, Singh N, Peters $\mathrm{H}$, et al. A randomized, prospective trial of stapled lung reduction versus laser bullectomy for diffuse emphysema. J Thorac Cardiovasc Surg 1996;111:317-22.

9. Pride NB, Permutt S, Riley RL, Bromberger-Barnea B. Determinants of maximal expiratory flow from the lungs. J Appl Physiol 1967;23:646-62.

10. Farstad T, Bratlid D. Effects of endotracheal tube size and ventilator settings on the mechanics of a test system during intermittent flow ventilation. Pediatr Pulmonol 1991;11:1521.

11. Corbeel LJ. Comparison between measurements of functional residual capacity and thoracic gas volume in chronic obstructive pulmonary diseases. Progr Respir Res 1969;4: 194-204.

12. Reichel G. Differences between intrathoracic gas measured by the body plethysmograph and functional residual capacity determined by gas dilution method. Progr Respir Res 1969; 4:188-93.

13. Roue C, Mal H, Sleiman C, Fournier M, Duchatelle JP, Baldeyrou $\mathrm{P}$, et al. Lung volume reduction in patients with severe diffuse emphysema: a retrospective study. Chest 1996; 110:28-34.

\section{Discussion}

Dr. Nasser K. Altorki (New York, N.Y.). Dr. Huh, I have a question about the validity of your model. With the inhalation of the elastase to induce emphysema, have you observed a homogeneous effect on the entire lung tissue, or have you perhaps selected some areas to be maximally affected by the elastase and others that were not?

Dr. Huh. We consider the pattern of emphysema induced as heterogeneous. We assessed the histologic findings of upper lobe, middle lobe, and lower lobe as separate specimens.

In each rabbit different degrees of emphysema were found on grading based on the different regions. Taking 
all rabbits together, we noted, as in humans, a trend toward greater disease in the upper lobes, probably reflective of greater ventilation. But the disease pattern does affect all lobes.

Dr. Joseph E. Bavaria (Philadelphia, Pa.). I liked your study very much. I wanted to ask you about the timing from the time of your initial insult to the time of lung volume reduction surgery. It seemed like you had your $30 \%$ or so increase in your lung volumes from preelastase to postelastase. If you waited for more time or if you maybe gave a second smaller dose or something like that, would that allow you to actually increase your volumes to the point where they were more matchable to a human, which is usually about $200 \%$ to $250 \%$ ?

Dr. Huh. We followed the pulmonary functions at intermediate intervals. At 2 weeks we saw an increase in the measured volumes, and at 4 weeks they had pretty much peaked out. I think waiting any longer would not produce any further increase in volumes, although studies need to be done to confirm this.

Dr. Larry R. Kaiser (Philadelphia, Pa.). When you follow these animals longer, I mean, is this a fatal injury? Do these animals die of end-stage disease or do you get to a certain point, that 4 weeks like you mentioned, and they just go on?

Dr. Huh. The fatalities actually occurred on the induction of emphysema. The 15,000 units of elastase caused approximately a $10 \%$ mortality from either an erosion into a blood vessel and hemorrhage or a pneumothorax. Once they successfully were induced, we had no fatalities after that, although we did not follow these animals longer than 4 weeks.

\section{ON THE MOVE?}

Don't miss a single issue of the journal! To ensure prompt service when you change your address, please photocopy and complete the form below.

Please send your change of address notification at least six weeks before your move to ensure continued service. We regret we cannot guarantee replacement of issues missed due to late notification.

\section{JOURNAL TITLE:}

Fill in the title of the journal here.

OLD ADDRESS:

Affix the address label from a recent issue of the journal here.

\section{NEW ADDRESS:}

Clearly print your new address here.

Name

Address

City/State/ZIP
COPY AND MAIL THIS FORM TO:

Periodical Subscription Services

Mosby, Inc.

11830 Westline Industrial Dr.

St. Louis, MO 63146-3318
OR FAX TO:

314-432-1158

N/ Mosby
OR PHONE:

1-800-453-4351

Outside the U.S., call

314-453-4351 